\title{
Contribuições do Software Scratch para Aprendizagem de Crianças com Deficiência Intelectual
}

\author{
Herik Zednik', Olga K. Takinami², Ronald Brasil Silva ${ }^{3}$, Selma Bessa Sales ${ }^{3}$, Sibere \\ Duarte de Araújo $^{3}$
}
Universidade Estadual do Piauí (UESPI) ${ }^{1}$,Secretaria da Educação de São Bernardo do $\mathrm{Campo}^{2}$, Secretaria Municipal da Educação (SME)/ Prefeitura Municipal de Fortaleza (PMF) ${ }^{3}$
\{selma.bessa, herik.zednik\} deducacao.fortaleza.ce.gov.br, \{brasil.ronald, olga.takinami, siberepsi\}@gmail.com

\begin{abstract}
The objective of this work is to report an experience with game development through the Scratch program as a didactic strategy to enhance the learning of children with intellectual disabilities (DI) who attend the Specialized Educational Assistance room. During the experiment, we sought to develop attention, concentration, perception, fine and broad motor coordination through personalized games to the students' specific needs. The experience has brought positive results, which lead to infer that the use of games contributes to the development of learning of children with ID. Qualitative analysis has also shown that games can have a positive emotional impact on students by favoring fun, engaging and dynamic activities.
\end{abstract}

Resumo. O objetivo deste trabalho é relatar uma experiência com desenvolvimento de jogos por meio do programa Scratch, como estratégia didática para potencializar o aprendizado de crianças com Deficiência Intelectual (DI) que frequentam a sala de Atendimento Educacional Especializado. Durante a experiência, buscou-se desenvolver habilidades de atenção, concentração, percepção, coordenação motora fina e ampla por meio de jogos personalizados às necessidades especificas dos alunos. A experiência trouxe resultados positivos, que levam a inferir que o uso de jogos colabora com o desenvolvimento da aprendizagem de crianças com DI. A análise qualitativa mostrou também que os jogos podem ter um impacto emocional positivo para os alunos, por favorecerem atividades divertidas, atraentes e dinâmicas.

\section{Introdução}

A utilização das Tecnologias Digitais (TD) nas escolas é algo cada vez mais comum e se estabelece como uma valiosa ferramenta na educação de jovens, adultos e crianças. Partindo de uma perspectiva inclusiva, o uso das tecnologias digitais também pode contribuir no desenvolvimento de processos mentais em crianças com Deficiência Intelectual (DI), facilitando sua aprendizagem e socialização.

Apesar de a educação ser um direito assegurado por meio da Constituição Federal de 1988 e, principalmente, a educação de pessoas com deficiência, conforme texto do inciso III, art. 208: "Atendimento educacional especializado aos portadores de deficiência, preferencialmente na rede regular de ensino", a inclusão ainda é um grande desafio. Isso requer esforço e consciência de todos os envolvidos nesse processo, família, escola, governo e sociedade. Não é suficiente, portanto, somente inserir a criança na escola, é necessário dar condições mínimas de estrutura (física e materiais pedagógicos), de pessoal qualificado e de metodologias adequadas ao desenvolvimento dessas crianças. 
VIII Congresso Brasileiro de Informática na Educação (CBIE 2019)

Anais do XXV Workshop de Informática na Escola (WIE 2019)

Nesse contexto, esta pesquisa relata a experiência de uso das TD como modo de contribuir, lúdica e construtivamente, com o desenvolvimento motor e cognitivo de crianças com Deficiências Intelectuais, por meio de jogos personalizados e adequados à necessidade de cada aluno e suas potencialidades, desenvolvidos na ferramenta Scratch.

A experiência foi motivada pela necessidade de potencializar o trabalho com crianças com deficiência, favorecendo seu aprendizado. Desse modo, os recursos tecnológicos, em especial o computador alinhado aos jogos eletrônicos, por serem recursos que possibilitam a participação efetiva dos alunos, proporcionando-lhes atividades práticas com base na solução de problemas, de modo dinâmico e divertido, foram usados como recursos para mediar o aprendizado de crianças com deficiência. Desse modo, o objetivo deste estudo é relatar uma experiência com desenvolvimento de jogos por meio do programa Scratch, como estratégia didática para potencializar o aprendizado de crianças com Deficiência Intelectual que frequentam a sala de Atendimento Educacional Especializado (AEE).

A metodologia utilizada neste estudo se caracteriza como relato de experiência, por meio de uma abordagem qualitativa com procedimento experimental, que tem como sujeitos de pesquisa os alunos matriculados na sala de AEE, da Escola Municipal de Educação Infantil e Ensino Fundamental Abnegado da Rocha Lima, localizada em Fortaleza.

Com o propósito de imergir nesse universo metodológico para compreendê-lo, atuar e produzir conhecimento de interesse da área da educação, este artigo está sequenciado, para melhor entendimento, na seguinte linha de pensamento: Introdução acerca do contexto no qual o tema se manifesta; a seção 2 aborda a linguagem e programação do Scratch e faz uma relação com a BNCC; a seção 3 apresenta o uso do Scratch na aprendizagem de crianças com deficiência intelectual; em seguida, as seções 4 e 5 descrevem o caminho metodológico e o relato de experiência, respectivamente. Finalmente, a seção 6 apresenta as observações finais.

\section{Linguagem de Programação Scratch e a BNCC}

O software Scratch foi escolhido por ser uma linguagem de programação criada para facilitar o aprendizado de Matemática e desenvolver a lógica computacional, é uma ferramenta lúdica e de fácil aprendizado, no qual é possível desenvolver animações, cartões, histórias interativas e jogos.

O Scratch foi criado em 2007 pelo Instituto Tecnológico de Massachussets (MIT), foi desenvolvido a partir da linguagem LOGO $^{1}$ para realizar programações através de blocos de encaixe, facilitando a utilização por crianças e iniciantes. A programação por bloco não exige conhecimentos prévios de programação. Atualmente está na versão 3.0 e pode ser utilizado diretamente da internet ou, se preferir, o usuário pode baixar a versão off-line no site $^{2}$.

A utilização do Scratch para alunos e professores mostra-se como uma excelente opção para estimular o desenvolvimento do aprendizado de forma criativa e divertida e, também, colabora na incorporação da Cultura Digital de modo a alinhar-se com as necessidades educacionais das novas gerações e com a BNCC.

Segundo Zednik, Dias e Almeida (2019, p.2), “[...] a BNCC indica a incorporação da Cultura Digital na escola, isso requer pensar sobre o uso das Tecnologias Digitais da Informação e Comunicação (TDIC) no desenvolvimento do currículo". Essa ideia se

\footnotetext{
${ }^{1}$ Logo, criado em 1967 por Seymour Papert, Wally Feurzeig e Cynthia Solomon, é uma linguagem de programação interpretada, voltada para crianças, jovens e até adultos. Foi utilizada com grande sucesso como ferramenta de apoio ao ensino regular e por aprendizes em programação de computadores.

${ }^{2}$ https://scratch.mit.edu/download
} 
VIII Congresso Brasileiro de Informática na Educação (CBIE 2019)

Anais do XXV Workshop de Informática na Escola (WIE 2019)

evidencia nas competências 4 e 5 da Base Nacional Comum Curricular - BNCC [Brasil 2018, p. 9]:

Competência 4: Utilizar diferentes linguagens - verbal (oral ou visual-motora, como Libras, e escrita), corporal, visual, sonora e digital, bem como conhecimentos das linguagens artística, matemática e científica, para se expressar e partilhar informações, experiências, ideias e sentimentos em diferentes contextos e produzir sentidos que levem ao entendimento mútuo.

Competência 5: Compreender, utilizar e criar tecnologias digitais de informação e comunicação de forma crítica, significativa, reflexiva e ética nas diversas práticas sociais (incluindo as escolares) para se comunicar, acessar e disseminar informações, produzir conhecimentos, resolver problemas e exercer protagonismo e autoria na vida pessoal e coletiva.

$\mathrm{Na}$ Competência 4, a palavra digital aparece como uma das linguagens que deve ser utilizada para desenvolver as habilidades humanas. A Competência 5 refere-se a utilização das tecnologias digitais de forma criteriosa, responsável e específica. Nesse sentido, é importante que o professor planeje suas ações considerando as especificidades de cada aluno e os objetivos que deseja alcançar. Para isso, faz-se necessário que o professor conheça as potencialidades de seus alunos de forma a criar um jogo adequado a cada criança.

\section{O Uso do Scratch na Aprendizagem de Crianças com Deficiência Intelectual}

A Deficiência Intelectual no contexto escolar requer do professor um olhar diferenciado na busca de metodologias que auxiliem a aprendizagem desses educandos. O uso de tecnologias digitais como jogos específicos pode contribuir no desenvolvimento dos processos mentais importantes para o aprendizado, como veremos logo adiante.

O Manual de Transtornos Mentais [DSM5 2014, p.33], produzido pela American Psychiatric Association, define que "Deficiência Intelectual (transtorno do desenvolvimento intelectual) é um transtorno com início no período do desenvolvimento que inclui déficits funcionais, tanto intelectuais quanto adaptativo, nos domínios conceitual, social e prático". E menciona os três critérios que devem ser preenchidos ao realizar o diagnóstico:

a) Déficits em funções intelectuais como raciocínio, solução de problemas, planejamento, pensamento abstrato, juízo, aprendizagem acadêmica, e aprendizagem pela experiência confirmada tanto pela avaliação clínica quanto por testes de inteligência padronizados e individualizados.

b) Déficits em funções adaptativas que resultam de fracassos para atingir padrões de desenvolvimento e socioculturais em relação à independência pessoal e responsabilidade social. Sem apoio continuado, os déficits de adaptação imitam o funcionamento em uma ou mais atividades diárias, como comunicação, participação social, e vida independente, e em múltiplos ambientes, como em casa, na escola, no local de trabalho e na comunidade.

c) Início dos déficits intelectuais e adaptativos durante o período de desenvolvimento.

Ainda de acordo com o DSM-5 (2014), a Deficiência Intelectual deve ser especificada de acordo com sua gravidade como: leve, moderada, grave, profunda. Essa definição se dá com base no funcionamento adaptativo e não apenas em escore de QI, sendo necessária para a realização do diagnóstico a observação de três aspectos conceituais: domínio conceitual, domínio social e domínio prático. 
VIII Congresso Brasileiro de Informática na Educação (CBIE 2019)

Anais do XXV Workshop de Informática na Escola (WIE 2019)

\subsection{Processos de aprendizagem em crianças com Deficiência Intelectual}

Muitos autores discorrem sobre as características fundamentais no processo de aprendizagem, tais como: metacognição, atenção, memória, motivação, transferência e como esse processo se apresenta em pessoas com Deficiência Intelectual.

Luria [apud Fonseca 2004] discorre que a Deficiência Intelectual ilustra certa desestruturação cognitiva do movimento voluntário e representa diversas disfunções nas unidades funcionais: atenção, processamento sequencial sucessivo e simultâneo e planificação do ato motor. Ele pontua que a atividade nervosa superior típica da deficiência apresenta lentidão na transmissão de influxo nervoso, perturbações no funcionamento dos analisadores (sistema funcional integrado que comporta os sentidos), subdesenvolvimento dos sistemas funcionais que traz perturbações motoras, quer na motricidade em geral, quer na fala em especial, assim como fragilidade no segundo sistema de sinalização, bem como na sua dinâmica, e ainda facilitação e inibição neurodinâmica e interativa alteradas, inércia do analisador motor que tende a provocar desorganização e instabilidade motora.

É importante perceber que as características específicas e peculiares da Deficiência Intelectual requerem situações de aprendizagem diferenciadas, com uso de diferentes ferramentas e estratégias pedagógicas, tanto em sala de aula regular, como no AEE.

O programa Scratch pode auxiliar na aprendizagem do aluno com deficiência intelectual porque permite a criação de vários recursos que podem estimular ou despertar o interesse dos alunos. Criar a animação do nome do aluno, por exemplo, de maneira que ele possa interagir com a animação ou mesmo participar da sua elaboração. Outra possibilidade seria a criação de jogos voltados aos interesses dos alunos respeitando o ritmo de cada um, ou seja, caso o aluno necessite de um tempo maior num jogo, isso pode ser realizado. É importante ressaltar que há a possibilidade de inserir a imagem do aluno no Scratch e isso torna o jogo personalizado e atraente para o usuário.

Uma vantagem desse software é que o Scratch permite que o próprio aluno programe sua animação, seu jogo e, esse processo de criação, pode ser muito interessante, uma vez que os alunos do AEE podem aprender a utilizar o Scratch e depois socializar com os demais colegas da sala de aula regular, eles podem compartilhar o que sabem com os demais alunos. O fato de a programação ocorrer por blocos, possibilita que alunos, mesmo que ainda não dominem a leitura convencional, possam programar. É possível ainda que o aluno tenha ajuda do professor para criar seu jogo, dizendo como quer criá-lo.

As possibilidades com o software Scratch são infinitas e atendem, segundo Sobreira (2013), a diversidade dos alunos em suas condições física, biológica e social com propostas que possibilitam que a aprendizagem ocorra de maneira significativa para todos.

\subsection{Contribuições do uso do Scratch na sala do AEE}

$\mathrm{O}$ uso de tecnologias como o Scracth pode auxiliar e favorecer o desenvolvimento de aprendizagens, visto que a construção do jogo pode ser direcionada a atender demandas especificas e criar situações de intervenções de acordo com as potencialidades e necessidades de cada aluno.

A aplicação dos jogos criados no Scratch ocorreu em uma Escola Municipal de Educação Infantil e Ensino Fundamental do município de Fortaleza, na Sala de Recursos 
VIII Congresso Brasileiro de Informática na Educação (CBIE 2019)

Anais do XXV Workshop de Informática na Escola (WIE 2019)

Multifuncionais - SRM, durante os atendimentos do AEE no contra turno da classe regular do aluno. Na referida unidade escolar estão matriculadas 32 crianças público-alvo da Educação Especial (autismo, deficiência, superdotação/altas habilidades) da Educação Infantil ao Fundamental I, tendo participado da pesquisa as com Deficiência Intelectual, totalizando 14 alunos, no intuito de promover um trabalho específico com esses educandos para favorecer a aprendizagem e desenvolver suas habilidades com auxílio dos jogos. De acordo com a Política Nacional de Educação Especial na Perspectiva da Educação Inclusiva (Brasil, 2007):

O atendimento educacional especializado tem como função: identificar, elaborar e
organizar recursos pedagógicos e de acessibilidade que eliminem as barreiras para a
plena participação dos estudantes, considerando suas necessidades específicas. As
atividades desenvolvidas no atendimento educacional especializado diferenciam-se
daquelas realizadas na sala de aula comum, não sendo substitutivas à escolarização.
Esse atendimento complementa e/ou suplementa a formação dos estudantes com
vistas à autonomia e independência na escola e fora dela.

Em conformidade com Zednik, Dias e Almeida (2019, p.2), as atividades com jogos requerem práticas colaborativas que reforçam o conceito de inteligência coletiva de Levy ${ }^{3}$, potencializando a interação entre os jogadores, que precisam trocar experiências e saberes para realizar as tarefas propostas. Compreendemos, portanto, que a utilização de jogos digitais pode estimular a criatividade e a aprendizagem em crianças, possibilitando intervenções pedagógicas específicas. De acordo com Gomes e Padovani (2005) jogos são softwares educacionais de sistemas de entretenimento o qual o usuário tem suas habilidades cognitivas desafiadas, motivando a ações que estimulam o aluno.

Para a criação desses jogos específicos, que estimulam funções cognitivas em crianças com DI, a professora do AEE contou com a participação do professor do Laboratório de Informática Educativa (LIE) que já desenvolve atividades ${ }^{4}$ com robótica, pensamento computacional, cultura maker, criação de jogos etc, como ferramentas de apoio para potencializar os processos de ensino e aprendizagem.

O processo de criação dos jogos iniciou com uma pesquisa envolvendo a professora do AEE, com a finalidade de registrar suas experiências, coletar dados e informações que ajudassem na criação dos jogos. Alguns jogos são versões digitalizadas de jogos manuais de tabuleiro e, a maioria, foi confeccionado com materiais reciclados de sucata, que foram adaptados para o formato digital.

Os jogos foram elaborados respeitando o grau de dificuldade e as limitações específicas das crianças atendidas no AEE, pois se considerou que um jogo com alto grau de dificuldade poderia desmotivar a criança, afinal, o objetivo principal da atividade não era finalizar o jogo, mas promover conexões cognitivas dos conteúdos trabalhados que ajudassem o desenvolvimento dos alunos.

Após a elaboração, foi realizada uma aplicação prática dos jogos com o objetivo de observar o interesse das crianças, o entusiasmo ao utilizar essa tecnologia e realizar os ajustes necessários, adequando os jogos a cada criança. As crianças começaram a pedir jogos personalizados ao seu gosto pessoal, uma das crianças relatou que o sonho dela era ser astronauta, então ela queria um jogo com um foguete e astronauta, outra aluna queria trocar as roupas da boneca.

A Figura 1 apresenta o fluxo de criação de jogos no Scratch.

\footnotetext{
${ }^{3}$ “"...] uma inteligência distribuída por toda parte, incessantemente valorizada, coordenada em tempo real, que resulta uma mobilização efetiva das competências [...]" (LÉVY, 2007)

${ }^{4}$ Ver, por exemplo, Silva et al (2018).
} 
VIII Congresso Brasileiro de Informática na Educação (CBIE 2019)

Anais do XXV Workshop de Informática na Escola (WIE 2019)
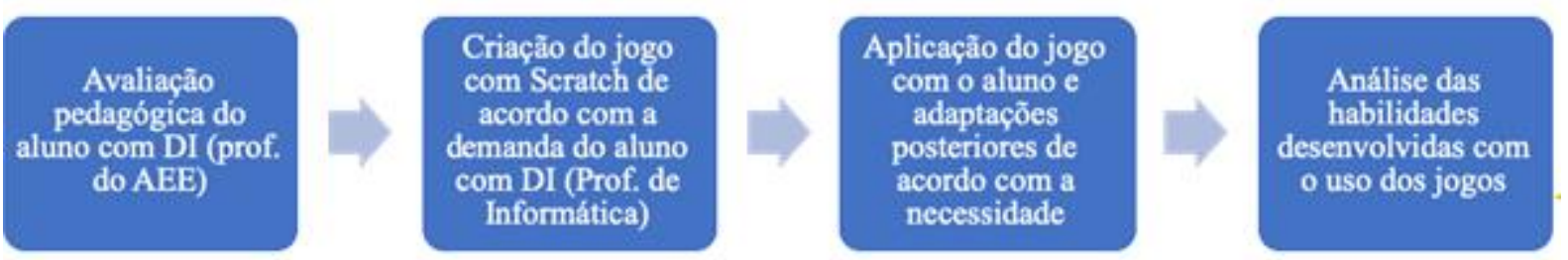

\section{Figura 1. Fluxo de criação dos jogos com Scratch} Fonte: próprio autor

Alunos com DI necessitam de estratégias especificas para superar suas dificuldades, com atividades direcionadas que estimulem funções cerebrais essenciais para a aprendizagem. Os jogos criados através do Scratch podem ser desenvolvidos para atingir habilidades que favoreçam a atenção, concentração, percepção, coordenação motora fina e ampla entre outras, visto que interagem através de imagens que podem ser colocadas e construídas de acordo com o interesse e a motivação da criança e das suas necessidades e preferências específicas, favorecendo a participação e o envolvimento nas atividades.

\section{Caminhos Metodológicos}

A finalidade principal desta pesquisa foi mostrar que o Scratch pode ser utilizado no AEE para apoiar o desenvolvimento da aprendizagem de crianças com DI e contribuir para a construção de processos mentais. A metodologia utilizada neste estudo se caracteriza como relato de experiência, pois busca descrever e analisar uma prática com a aplicação de métodos e técnicas diferenciadas do uso comum.

Inicialmente foi realizada uma revisão bibliográfica, em obras de autores como Lúria (2004), Zednik, Dias e Almeida (2019) e Gomes e Padovani (2005). Também foram apreciados documentos como a BNCC (2018) e Manual de Transtornos Mentais [DSM5 2014]. Em seguida, coletamos os dados através de pesquisa de campo realizada na Escola Municipal de Educação Infantil e Ensino Fundamental Abdenago da Rocha Lima, localizada em Fortaleza/Ce. Brasil. Onde foram efetuadas as observações e registros de 14 crianças com laudo diagnóstico de DI durante os atendimentos semanais na sala do AEE.

Quanto à abordagem, este estudo se caracteriza como uma pesquisa qualitativa com procedimento experimental, tendo em vista que procuramos entender os fenômenos que se encontram no uso de jogos criados por meio do Scratch e aplicados em crianças com DI, segundo as perspectivas dos sujeitos envolvidos nesta pesquisa.

Os laudos das 14 crianças (sujeitos da pesquisa) apresentavam diagnósticos entre nível de gravidade leve e moderado. Respeitando o sigilo ético, não mencionaremos os nomes das crianças envolvidas na pesquisa, apenas utilizaremos a nomenclatura de S1 ao S14. A seguir, no Quadro 1 uma breve descrição de cada sujeito participante:

\begin{tabular}{|l|l|l|l|l|}
\hline ALUNO & IDADE & SÉRIE & TURNO & LAUDO MÉDICO \\
\hline S1 & 07 anos & $1^{\circ} \mathrm{B}$ & Manhã & DI Não especificada CID-10 F79 \\
\hline S2 & 07 anos & $1^{\mathbf{o}} \mathrm{A}$ & Tarde & DI leve CID-10 F70 \\
\hline S3 & 10 anos & $3^{\mathbf{o}} \mathrm{A}$ & Tarde & DI moderada CID-10 F71 \\
\hline S4 & 08 anos & $3^{\mathbf{o}} \mathrm{A}$ & Tarde & DI leve CID-10 F70 \\
\hline S5 & 08 anos & $3^{\mathbf{o}} \mathrm{B}$ & Tarde & DI leve CID-10 F70 \\
\hline S6 & 10 anos & $4^{\mathbf{o}} \mathrm{A}$ & Manhã & DI leve CID-10 F70 \\
\hline S7 & 10 anos & $4^{\mathbf{o}} \mathrm{A}$ & Tarde & DI leve CID-10 F70 \\
\hline S8 & 09 anos & $4^{\mathbf{o}} \mathrm{B}$ & Tarde & DI leve CID-10 F70 \\
\hline S9 & 12 anos & $4^{\mathbf{o}} \mathrm{B}$ & Tarde & DI leve CID-10 F70 \\
\hline S10 & 14 anos & $5^{\mathbf{o}} \mathrm{A}$ & Manhã & DI moderada CID-10 F71 \\
\hline S11 & 11 anos & $5^{\mathbf{o}} \mathrm{A}$ & Manhã & DI leve CID-10 F70 \\
\hline
\end{tabular}


VIII Congresso Brasileiro de Informática na Educação (CBIE 2019)

Anais do XXV Workshop de Informática na Escola (WIE 2019)

\begin{tabular}{|l|l|l|l|l|}
\hline S12 & 10 anos & $5^{\circ} \mathrm{A}$ & Manhã & DI leve CID-10 F70 \\
\hline S13 & 10 anos & $5^{\circ} \mathrm{A}$ & Tarde & DI leve CID-10 F70 \\
\hline S14 & 11 anos & $5^{\circ} \mathrm{A}$ & Tarde & DI leve CID-10 F70 \\
\hline
\end{tabular}

Quadro 1. Diagnóstico dos sujeitos da pesquisa

Fonte: Pesquisa de Campo (fevereiro/março/abril/maio/junho-2019)

Por ser uma pesquisa que busca investigar as contribuições dos jogos criados com o Scracht como ferramenta para apoiar o desenvolvimento da aprendizagem em crianças com DI, os jogos foram aplicados durante os atendimentos semanais no AEE.

Os dados foram organizados através de observações contínuas, anotações, registros, fotos, vídeos, realizados durante a aplicação dos jogos criados com o Scracht nos atendimentos do AEE. A coleta de dados foi realizada durante os meses de fevereiro a junho de 2019, em 02 sessões semanais com duração de 40 a 50 minutos.

\section{Relato da experiência}

Através da utilização do software Scratch foi possível desenvolver jogos diferenciados que atendam às necessidades de cada educando com DI. O estudo bibliográfico e a análise das aplicações dos jogos possibilitaram uma reflexão acerca da utilização dos jogos na aprendizagem de crianças com DI, como ferramenta de intervenção pedagógica.

Durante a pesquisa de campo foi perceptível a participação e a integração das crianças envolvidas na pesquisa, onde os jogos foram desenvolvidos para atender as especificidades dos alunos (Quadro 2), favorecendo o desenvolvimento de habilidades como: a atenção, a concentração e percepção, entre outros processos mentais fundamentais para o aprendizado.

\begin{tabular}{|c|c|c|c|}
\hline \multicolumn{4}{|c|}{ Jogos desenvolvidos com Scratch $\mathbf{x}$ Habilidades contempladas } \\
\hline Jogo & Tipo & Principais Habilidades & Endereço eletrônico \\
\hline $\mathrm{J} 1$ & Roupas & $\begin{array}{l}\text { Atenção, concentração e memória } \\
\text { visuoconstrutiva. }\end{array}$ & https://scratch.mit.edu/projects/327644642/ \\
\hline $\mathrm{J} 2$ & Animais & Memória, atenção e percepção. & https://scratch.mit.edu/projects/267221244/ \\
\hline $\mathrm{J} 3$ & Vogais & $\begin{array}{l}\text { Atenção, percepção e memória } \\
\text { operacional. }\end{array}$ & https://scratch.mit.edu/projects/267238240/ \\
\hline $\mathrm{J} 4$ & Frutas & $\begin{array}{l}\text { Atenção, percepção e memória } \\
\text { visuoconstrutiva. }\end{array}$ & https://scratch.mit.edu/projects/267231790/ \\
\hline $\mathrm{J} 5$ & Numerais & Atenção, percepção e raciocínio lógico. & https://scratch.mit.edu/projects/267237453/ \\
\hline $\mathrm{J} 6$ & $\begin{array}{l}\text { Formar } \\
\text { Palavras }\end{array}$ & Memória, atenção e concentração. & https://scratch.mit.edu/projects/267230925/ \\
\hline $\mathrm{J} 7$ & Futebol & $\begin{array}{l}\text { Atenção alternada, concentração e } \\
\text { percepção. }\end{array}$ & https://scratch.mit.edu/projects/267225748/ \\
\hline $\mathrm{J} 8$ & Cores & $\begin{array}{l}\text { Atenção, percepção e memória } \\
\text { visuoconstrutiva. }\end{array}$ & https://scratch.mit.edu/projects/267229837/ \\
\hline
\end{tabular}

Quadro 2. Jogos desenvolvidos com Scratch $x$ Habilidades contempladas Fonte: Pesquisa de Campo (fevereiro/março/abril/maio/junho2019) 
VIII Congresso Brasileiro de Informática na Educação (CBIE 2019)

Anais do XXV Workshop de Informática na Escola (WIE 2019)

Observamos durante a aplicação ${ }^{5}$ dos jogos propostos (ver Quadro 2) uma menor saturação e um aumento da autonomia a partir da utilização do Scratch, proporcionado pelas inúmeras possibilidades que a ferramenta dispõe para adequar à demanda do aluno. O Quadro 3 , a seguir, através dos registros de avaliações individuais contínuas nos aspectos positivos comportamentais e cognitivos, relaciona os jogos com os quais cada aluno interagiu durante a experiência assim como as contribuições adquiridas.

\begin{tabular}{|c|c|c|c|c|c|c|c|c|}
\hline \multicolumn{8}{|c|}{$\begin{array}{l}\text { Alunos participantes } \mathbf{x} \text { Jogos } \\
\text { utilizados }\end{array}$} & \multirow[t]{2}{*}{ Contribuições promovidas a partir do uso dos jogos } \\
\hline SUJEITO & $\mathrm{J} 1$ & $\mathrm{~J} 2$ & $\mathrm{~J} 3 \mathrm{~J}$ & $\mathrm{~J} 4 \mathrm{~J} 5$ & $\mathrm{~J} 6$ & $\mathrm{~J} 7$ & $\mathrm{~J} 8$ & \\
\hline S1 & $\mathrm{X}$ & $\mathrm{X}$ & $\mathrm{x} \mid \mathrm{X}$ & $\mathrm{X} \mid \mathrm{X}$ & & $\mathrm{X}$ & $\mathrm{X}$ & $\begin{array}{l}\text { Diminuição da agitação motora; maior tempo na atenção e } \\
\text { concentração nas atividades habituais; }\end{array}$ \\
\hline S2 & $\mathrm{X}$ & $\mathrm{X}$ & $x \mid x$ & $\mathrm{X} \mid \mathrm{X}$ & & $\mathrm{X}$ & $\mathrm{X}$ & $\begin{array}{l}\text { Melhora no tempo de atenção, concentração e foco durante os } \\
\text { jogos; }\end{array}$ \\
\hline S3 & $\mathrm{X}$ & $\mathrm{X}$ & $\mathrm{X}$ & $\mathrm{X} \mid \mathrm{X}$ & & $\mathrm{X}$ & $\mathrm{X}$ & $\begin{array}{l}\text { Menor saturação durante a realização dos jogos, maior tempo para } \\
\text { manter a concentração e atenção; }\end{array}$ \\
\hline S4 & $\mathrm{X}$ & $\mathrm{X}$ & $X \mid x$ & $\mathrm{X} \mid \mathrm{X}$ & & $\mathrm{X}$ & $\mathrm{X}$ & Menor saturação e menor agitação motora; \\
\hline S5 & $\mathrm{X}$ & $\mathrm{X}$ & & & $\mathrm{X}$ & $\mathrm{X}$ & $\mathrm{X}$ & $\begin{array}{l}\text { Maior tempo de concentração e melhora no aspecto da escrita de } \\
\text { palavras; }\end{array}$ \\
\hline S6 & $\mathrm{X}$ & $\mathrm{X}$ & & & $\mathrm{X}$ & $\mathrm{X}$ & $\mathrm{X}$ & Menor agitação motora e menor saturação; \\
\hline S7 & $\mathrm{X}$ & $\mathrm{X}$ & & & $\mathrm{X}$ & $\mathrm{X}$ & $\mathrm{X}$ & $\begin{array}{l}\text { Maior desenvolvimento da escrita de palavras, melhora nos } \\
\text { aspectos relacionados à memória; }\end{array}$ \\
\hline S8 & $\mathrm{X}$ & $\mathrm{X}$ & & & $\mathrm{X}$ & $\mathrm{X}$ & $\mathrm{X}$ & Maior tempo para manter o foco, atenção e concentração; \\
\hline S9 & $\mathrm{X}$ & $\mathrm{X}$ & & & $\mathrm{X}$ & $\mathrm{X}$ & $\mathrm{X}$ & $\begin{array}{l}\text { Melhoria nos aspectos relacionados à atenção e percepção de } \\
\text { imagens; }\end{array}$ \\
\hline S10 & & $\mathrm{X}$ & $\mathrm{X}$ & $\mathrm{X}$ & & $\mathrm{X}$ & & $\begin{array}{l}\text { Menor saturação, melhoria na coordenação visio manual, menor } \\
\text { agitação motora e maior concentração }\end{array}$ \\
\hline S11 & $\mathrm{X}$ & $\mathrm{X}$ & & & $\mathrm{X}$ & $\mathrm{X}$ & $\mathrm{X}$ & $\begin{array}{l}\text { Aumento da atenção, concentração, foco, percepção, melhoria no } \\
\text { reconhecimento de letras; }\end{array}$ \\
\hline $\mathrm{S} 12$ & $\mathrm{X}$ & $\mathrm{X}$ & & & $\mathrm{X}$ & X & $X$ & $\begin{array}{l}\text { Melhora nos aspectos percepção, atenção, foco, concentração e na } \\
\text { escrita de palavras; }\end{array}$ \\
\hline $\mathrm{S} 13$ & $\mathrm{X}$ & $\mathrm{X}$ & & & $\mathrm{x}$ & X & $\mathrm{X}$ & $\begin{array}{l}\text { Menor agitação motora, menor saturação nas atividades, maior } \\
\text { tempo de concentração e atenção; }\end{array}$ \\
\hline S14 & $\mathrm{X}$ & $\mathrm{X}$ & & & $\mathrm{X}$ & $\mathrm{X}$ & $\mathrm{X}$ & $\begin{array}{l}\text { Melhora nos aspectos percepção, atenção, foco, concentração na } \\
\text { escrita de palavras. }\end{array}$ \\
\hline
\end{tabular}

Quadro 3. Alunos participantes x Jogos utilizados
Fonte: Pesquisa de Campo (fevereiro/mar/abril/maio/junho2019)

Com os resultados individuais da pesquisa realizada com os sujeitos envolvidos, infere-se, com base nas respostas apresentadas durante as aplicações dos jogos, que o Scratch possibilita de forma simples, prazerosa e criativa a manipulação do jogo de acordo com o nível de habilidade e potencialidade de cada sujeito, o que torna a ferramenta um diferencial para alcançar aprendizagens significativas, pois permite a criação de jogos que favorecem a

\footnotetext{
${ }^{5}$ Ver, a respeito em Scratch \& AEE, disponível em, http://bit.ly/21XPvlpscratchAEE>, acesso em Abril de 2019.
} 
VIII Congresso Brasileiro de Informática na Educação (CBIE 2019)

Anais do XXV Workshop de Informática na Escola (WIE 2019)

aprendizagem respeitando as diversidades e especificidades de alunos com DI, despertando o interesse em aprender e desenvolver suas potencialidades.

Outro aspecto observado durante a análise qualitativa é que as estratégias envolvendo jogos impactaram emocionalmente e de modo positivo os alunos envolvidos, por proporcionar atividades mais divertidas, atraentes e dinâmicas.

A experiência foi desenvolvida em quatro etapas descritas a seguir: 1 - realização de avaliação diagnóstica inicial dos sujeitos da pesquisa, realizada pela professora do AEE, apresentando as principais dificuldades e potencialidades dos participantes. 2 - reflexão e planejamento com o professor do LIE acerca das informações relevantes para a construção dos jogos. 3 - aplicação das atividades/jogos - nessa etapa utilizou-se a Sala de Recursos Multifuncionais da escola e teve início em fevereiro, sendo de responsabilidade da professora do AEE. Os jogos eram selecionados e aplicados de acordo com a habilidade que precisava ser desenvolvida com cada aluno, e os resultados registrados em folha de registro diário do AEE, onde consta: atividade realizada pelo aluno, habilidade contemplada pela atividade, objetivos da atividade, avanços e dificuldades encontradas pelo aluno, data e assinatura da professora do AEE. 4 - avaliação dos jogos que foram utilizados (saber se alcançaram os objetivos), análise dos registros realizados durante as aplicações, aplicação da segunda avaliação diagnóstica dos alunos, sugestões de adaptações e melhorias dos jogos feitas em conjunto com a professora do AEE e o professor do LIE com a finalidade de aprimoramento.

Ressalta-se que a ordem utilizada na aplicação dos jogos não afeta o resultado, porém é importante salientar que o desenvolvimento de qualquer atividade envolvendo alunos com DI é necessário sistematização e regularidade, para que seja facilitado o processo de neuroplasticidade cerebral, que são as modificações cerebrais realizadas através de estímulos externos que possibilitam a criação de sinapse, novas conexões, gerando aprendizados. Assim a repetição e o uso contínuo dos jogos contribuíram nesse processo.

O desenvolvimento dos processos mentais em crianças com DI visa à superação das dificuldades trazidas pelos alunos e tenta minimizar os impactos causados pelas deficiências escolar e social. Os jogos criados não trabalham diretamente sobre os conteúdos escolares, mas sim nos processos mentais que facilitam a aprendizagem dos conteúdos propostos.

\section{Considerações Finais}

Apesar de o Scratch ser um software que pode favorecer a autoria e o protagonismo infantil, neste trabalho optou-se por ofertar inicialmente jogos preparados pelo professor, atendendo interesses e especificidades dos sujeitos da pesquisa. Uma vez que o aluno com DI consegue identificar um jogo de seu interesse, consequentemente ele pode manifestar seu desejo por um tema aprazível. O fato de se apresentar um jogo pronto com base nas especificidades dos alunos, portanto, objetiva que eles consigam alcançar, de maneira concreta e personalizada, o desenvolvimento de habilidades.

Para trabalhos futuros, numa segunda etapa da pesquisa, visamos implementar uma proposta de trabalho com o pensamento computacional para que os alunos compreendam conceitos como o de Algoritmos, com o intuito de fomentar o entendimento de como ocorre a programação. Atendendo à necessidade de se trabalhar de maneira concreta, acreditamos que atividades de pensamento computacional poderiam ocorrer de maneira desplugada, ou seja, com atividades no pátio da escola, com jogos de percurso, por exemplo. Nessas atividades, além de trabalhar de maneira concreta conceitos como o de Algoritmo, trabalham-se conceitos de lateralidade, cores etc, e, também, promove o trabalho com equipes. 
VIII Congresso Brasileiro de Informática na Educação (CBIE 2019)

Anais do XXV Workshop de Informática na Escola (WIE 2019)

Paralelamente planeja-se oferecer uma formação aos professores da escola acerca do Scratch, com a finalidade de estimular o corpo docente a visualizar as diversas possibilidades pedagógicas, de modo que incluam todos os alunos da escola e que contemplem as múltiplas inteligências: lógico-matemática, corporal cinestésica, espacial, musical, linguística, interpessoal e intrapessoal.

Dessa maneira, queremos evidenciar com este trabalho inicial, que é possível trabalhar a programação com crianças diagnosticadas com DI e promover uma educação que verdadeiramente seja inclusiva, especificamente utilizando a ferramenta Scratch.

\section{Referências}

American Psychiatric Association - APA. (2014) "Manual diagnóstico e estatístico de transtornos mentais: DSM-5". 5. ed. Porto Alegre: Artmed, p, 34.

Brasil. (2018) "Base nacional comum curricular" Ministério da Educação. Secretaria da Educação Básica. Brasília, DF. Disponível em: < http://basenacionalcomum.mec.gov.br/wp-content/uploads/2018/02/bncc-20dez-site.pdf >. Acesso em: mar. 2019.

(2009) "Diretrizes Operacionais para o Atendimento Educacional Especializado na Educação Básica, modalidade Educação Especial" Resolução $n^{0}$ 4, de 02 de outubro de 2009. Ministério da Educação/ Conselho Nacional de Educação/ Câmara de Educação Básica. Brasília.

- (2007) "Política Nacional de Educação Especial na Perspectiva da Educação Inclusiva" Ministério da Educação/Secadi. Disponível em: < http://portal.mec.gov.br/index.php?option=com_docman\&view=download\&alias $=16690$ politica-nacional-de-educacao-especial-na-perspectiva-da-educacao-inclusiva05122014\&Itemid=30192> . Acesso em 1 fev. 2019.

(1988).“Constituição da República Federativa do Brasil de 1988”. Brasília, DF: Presidência da República,. em: $<$ http://www.planalto.gov.br/ccivil_03/Constituicao/Constituiçao.htm. $>$ Acesso em 1 fev. 2019.

Fonseca, V. (2004) "Psicomotricidade: Perspectivas multidisciplinares". Porto Alegre: Artmed, p. 106.

Gomes, Alex Sandro; Padovani, Stephania (2005) "Usabilidade no ciclo de desenvolvimento de software educativo" In: XVI Simpósio Brasileiro de Informática na Educação SBIE 2005, Juiz de Fora (MG). Anais do XVI Simpósio Brasileiro de Informática na Educação.

Lévy, Pierre. (2007) "Inteligência coletiva. Para uma antropologia do ciberespaço". 5a ed. [S.1.]: Loyola.

Sobreira, Elaine Silva Rocha; Takinami, Olga Kikue; Santos, Verônica Gomes dos. (2013) "Programando, Criando e Inovando com o Scratch: em busca da formação do cidadão do século XXI". Anais da JAIE. Disponível em $<$ http://www.brie.org/pub/index.php/pie/article/view/2592/2248>. Acesso em 12 de maio de 2019.

Zednik, Herik; Dias, Bruno Pereira; Almeida, Talia da Silva. (2019) "Educação Gamificada: Estratégia Didática para a Formação de Professores" I Simpósio Internacional e IV Nacional de Tecnologias Digitais na Educação - IV - SNTDE 2019, São Luis, Maranhão. 